\title{
Role of intrauterine insemination in infertile couple seeking care at Acharya Vinobha Bhave rural tertiary care hospital
}

\author{
Sanjana Sunil Khemka*, Deepti Shrivastava, C. Hariharan, Arpita Jaiswal
}

Department of Obstetrics \& Gynaecology, Jawaharlal Nehru Medical College, Sawing Megohm, Wardha, M.H., India

Received: 24 November 2014

Accepted: 12 December 2015

\section{*Correspondence:}

Dr. Sanjana Sunil Khemka,

E-mail: drsanjanakhemka@yahoo.com

Copyright: (C) the author(s), publisher and licensee Medip Academy. This is an open-access article distributed under the terms of the Creative Commons Attribution Non-Commercial License, which permits unrestricted non-commercial use, distribution, and reproduction in any medium, provided the original work is properly cited.

\begin{abstract}
Background: Fibroids Infertility affects between 60 million to 68 million people worldwide; generally one in ten couples experience primary or secondary infertility. The majority of those who suffer, live in the developing world. Universally, the prevalence rises significantly with a woman's age. The WHO estimates the overall prevalence of infertility in India to be between 3.9 and 16.8 per cent. Objective: To assess the outcome of intrauterine insemination (IUI) amongst infertile couples seeking care at AVBRH. And to correlate the outcome of IUI with various parameters associated with infertility.

Methods: 50 patients undergoing 72 stimulated IUI cycles between September 2012 and august 2014. It was a prospective interventional study. Interventions: Ovarian stimulation with clomifene citrate \& gonadotrophins was initiated and a single IUI was performed $36 \mathrm{~h}$ after triggering ovulation. Main outcome: Pregnancy rates by urine pregnancy test per couple. Pregnancy rates by urine pregnancy test per cycle. Secondary outcome: livebirth, on-going PR, abortion rate.

Results: The pregnancy rate per couple and per cycle were $22 \%$ and $15.27 \%$ respectively. Live birth were $8 \%$, ongoing pregnancy was $4 \%$, abortions were $10 \%$.

Conclusions: On the basis of analysis of successful outcome of IUI it can be said that the patients with best prognosis are the one with age $<30$ years, lesser duration of infertility, good motile spermatozoa, preovulatory follicle, good endometrial thickness, \& semen preparation are certainly the cornerstones for successful intrauterine insemination.
\end{abstract}

Keywords: Pregnancy rate, Intrauterine insemination, Cumulative pregnancy rate

\section{INTRODUCTION}

The wish for a child is not only a deeply felt need originating from individual instincts but it also depends on the development of individual personality, sociocultural processes, economic factors, individual biographical changes, fate, interpersonal processes between partners and family dynamics.

Failure to meet that is associated with physical as well as mental stress. The word infertility is highly stigmatised and leads to profound social consequences for infertile couple hence word subfertility is used synonymously in absent of major/uncorrectable causative factor.

According to $\mathrm{WHO}^{1}$ a couple may be considered infertile if after one year of regular sexual intercourse, without contraception, the woman has failed to conceive and there is no other reason, (such as breastfeeding or postpartum amenorrhoea). The term infertility is generally used to denote that couple has reduced chances to conceive as compared to the general population.

Infertility affects between 60 million to 68 million people worldwide, ${ }^{2,3}$ generally one in ten couples experience 
primary or secondary infertility. The majority of those who suffer, live in the developing world. Universally, the prevalence rises significantly with a woman's age. The WHO estimates the overall prevalence of infertility in India to be between 3.9 and 16.8 per cent. ${ }^{2,3}$

Fecundity ${ }^{4}$ is the rate of conception in the population in a given time period, usually 1 month, and is around $20 \%$. Fecundability ${ }^{4}$ refers to probability of pregnancy per cycle.

Intrauterine insemination is the deposition of washed and capacitated sperm into the uterine cavity and remains one of the most popular techniques for the indications - Mild male factor infertility, unexplained infertility, PCOS - as an adjunct to ovulation induction, mild endometriosis, tubo-periotoneal factors in a young patient with at least one functional and patent fallopian tube.

The rationale use of IUI is to reduce the effect of factors such as vaginal acidity and cervical mucus hostility and to benefit from deposition of bolus of concentrated motile morphologically normal sperm as close possible to oocytes.

IUI is recommended for those couple where there is insufficiency of good quality sperm reaching the upper reproductive tract of female partners 11. Intrauterine insemination is an effective, non-invasive, simple and cost effective first line treatment for infertile couples. Ovulation induction together with intrauterine insemination (IUI) remains a mainstay of infertility therapy.

Protocols for Controlled Ovarian Stimulation $(\mathrm{COH})$ in patients undergoing ovulation induction therapy have frequently utilized Clomiphene Citrate (CC) as first-line therapy. ${ }^{5}$

$\mathrm{CC}$ remains the first choice in the management of infertility in an-ovulatory women and has also been shown to be efficacious in normally ovulating women with inadequate follicular or luteal development. Reported pregnancy rates per cycle for IUI range from 8 to $22 \%{ }^{6}$

The pregnancy rates per IUI cycle are quite variable in the literature due to differences in cause and duration of infertility, concomitant usage or omission of ovarian stimulation, sperm preparation techniques, treatment cycles and number of times IUI is performed during a cycle (single or double). ${ }^{7,8}$

Generally, four cycles of $\mathrm{COH} / \mathrm{IUI}$ are recommended depending on the female age prior to moving on In Vitro Fertilization (IVF). ${ }^{9}$

The present study was planned to analyse the success of Intrauterine Insemination with our newly established IUI lab at this rural medical college.

\section{Aim and objectives}

1. To assess the outcome of intrauterine Insemination (IUI) amongst infertile couples seeking care at AVBRH.

2. To correlate the outcome of IUI with various parameters associated with infertility.

\section{METHODS}

It is a prospective interventional study. 50 Cases were selected 2 years duration of study statistically student's ttest was used place: Acharya Vinobha Bhave rural tertiary care hospital Sawangi Meghe Wardha.

\section{Inclusion criteria for AIH}

Mild male factor infertility, mild asthenozoospermia (gr1-2), oligozoospermia ( $\geq 5$ million), unexplained infertility, endometriosis - minimal \& mild endometriosis, male immunological infertility, structural and other defects of male partner like hypospadias, epispadias, chordee, varicocoele.

\section{Exclusion criteria}

Active inflammatory disorders of female genital tract, any evidence of tubal factor of female infertility not resolved by fallopian tube recanalization/hysterscopic cannulation, positive history of HIV or HBsAG or other venereal diseases in husband, severe male factor infertility when the mean total motile sperm count is $<5$ million.

\section{Main outcome}

- $\quad$ Pregnancy rates by urine pregnancy test per couple.

- Pregnancy rates by urine pregnancy test per cycle.

\section{Secondary outcomes}

- $\quad$ Live birth rates per cycle, per couple.

- On-going pregnancy rates per cycles, per couple.

- Abortion rate per cycle, per couple.

50 women with infertility attending obstetrics and gynaecology OPD were included in the study. Preliminary details in the form of name, age, address, socioeconomic status, occupation, education and registration number were noted. Complete history regarding their duration and type of infertility, menstrual pattern especially the presence of any irregularity, coital difficulties, complete obstetric history in case of secondary infertility, any history of drug intake and their duration, chronic illness, semen analysis, D3 hormonal assessment in form of serum FSH, LH, prolactin, AMH, were obtained if patient was affording. Any diagnostic procedure in form of folliculometry, HSG, laparoscopy was recorded in the pre designed proforma. Female 
partner were checked out for tubal patency and other gross pathologies. Basic semen analysis of husband was done to know different characteristics and quality of sperms.

\section{Ovarian stimulation protocol}

Initial 22 female partners were induced for ovulation by clomiphene citrate (Fertomid/clomipure/) 50-100 mg once a day for 5 day from second day of menstruation counting from $1^{\text {st }}$ day of last menstrual period, and follicular study was planned by trans vaginal ultra sonography from $7^{\text {th }}$ day of first day of last menstrual period. With increasing level of confidence in later phase of study we gave HMG, 75-150 IU in non PCOD women and FSH 75-150IU in PCOD patient depending upon there size of follicle, number of follicles and endometrial thickness on day 7, 9 and 11 of cycle, counting from first day of menstrual cycle. When the dominant follicle attained size of $16 \mathrm{~mm}$, human chorionic gondotrophin injection 5000-10000 IU intramuscular was administered.

\section{Semen preparation}

Husband semen was used after prior consent. The husband was explained about the procedure and asked to collect the semen by masturbation after abstinence of 2-3 days. Processing of semen was done by single layer density gradient method.

Prior to Insemination consent of both husband and wife was taken. IUI was done 18 hours after hCG administration. A total of $0.5-1 \mathrm{ml}$ was inseminated. All Women remained in supine position for 20-30 minutes. Single insemination was considered for each patient. Patient was given luteal phase support in form of Tab Dydrogestrone (Duphaston) $1 \mathrm{BD}$ orally for 10 days and tab naturogest vaginal pessary $200 \mathrm{mg} \mathrm{HS}$ and was followed till next menses. If no menses occurred then urine pregnancy test was done after one week of expected menstrual period to confirm pregnancy otherwise further options of IUI was given for maximum three of cycles if menses occurred.

\section{Statistical analysis}

The data obtained, was evaluated by Chi-square test. Probability (P) values $<0.05$, were regarded as statistically significant. Sample size was selected after consultation with statistician using 95\% confidence interval. Software used in the analysis was SPSS-17.0.

\section{RESULTS}

The present study was carried out in the department of obstetrics and gynaecology at Acharya Vinoba Bhave rural hospital, Sawangi, Wardha from September 2012 to august 2014. 50 cases of infertility who attended the out patients department of obstetrics and gynaecology were included and given 72 IUI cycles.
Out of 50 patients, 11 patients got pregnant and rest 39 had failure of pregnancy after intrauterine insemination. Successful pregnancy achieved by intrauterine insemination, pregnancy rate was $22 \%$ per patient and $15.27 \%$ per IUI cycle.

The mean age of infertile women were $28.27 \pm 3.69$ years, range being minimum 22 years and maximum 38 years.

The mean age of male were $34.55 \pm 5.47$ years, range being minimum 32 years and maximum 40 years.

In present study it shows that majority of woman participants had regular menstrual cycles 32 (64\%), whereas rest $18(36 \%)$ had irregular menstrual cycles.

In present study primary infertility was significantly high $40(80 \%)$ and secondary infertility was $10(20 \%)$ which was statistically significant $(\mathrm{P}=0.001)$.

In present majority of male participants $36(72 \%)$ had normal sperm count which was statistically significant, above 20 millions and remaining 14 (28\%) had sperm count below 20 millions.

Abnormal semen parameter were found in 14 men i.e. asthenospermia was present in $4(29 \%)$, pyospermia was $3(21 \%)$, teratospermia was $1(7 \%)$, oligoasthenospermia was present in $6(43 \%)$ of male participant.

In present study, majority of woman participants had 23 $(46 \%)$ had bilateral patent tube which was statistically significant, $5(10 \%)$ had unilateral patent tube, and 11 $(22 \%)$ underwent fallopian tube recanalization and rest $11(22 \%)$ patients were checked for tubal patency by laparoscopic chromoperturbation.

Majority of women participants had normal ultrasonography finding which was statistically significant. Out of which 11 patient who were checked for tubal patency by laparoscopy.

Majority of woman participants in study group had monofollicular response which was statistically significant. 1 preovulatory follicle was present in 30 $(60 \%), 2$ or 3 was present in $16(32 \%), 4$ or more was present in $4(8 \%)$ of women participants.

In present study majority of patients were given $\mathrm{CC}+\mathrm{hCG}$ protocol $22(44 \%), \mathrm{CC}+\mathrm{HMG}+\mathrm{hCG}$ protocol was given in $17(34 \%)$, non PCOS patient, $10(20 \%)$ were given $\mathrm{CC}+\mathrm{FSH}+\mathrm{hCG}$ in $\mathrm{PCOS}$ patient, and 1 patient was given $\mathrm{CC}+\mathrm{HMG}+\mathrm{GnRHA}$ for trigger.

\section{DISCUSSION}

Intrauterine insemination (IUI) was initially reported by Cohen in 1962. It has since, become a widely utilized technique for treatment of infertility. Indication for its use 
have been varied, and also used empirically. IUI is most simple, easy and popular assisted reproductive technique practised today. The main idea of IUI is to increase the availability of physiologically competent spermatozoa at close proximity of the ovulated oocyte, usually at ampullary site of fallopian tube, so that easy fertilization can takes place. The steps involved in IUI from collection of semen to insemination of prepared sperm suspension inside the uterine cavity, should be such that, the whole procedure does not become detrimental to the sperm, its DNA integrity is preserved and fertilization capacity is maintained.

In present study we found that $80 \%$ of patients had primary infertility, and $20 \%$ patients had secondary infertility. Number of primary infertility was statistically significant $P$ value 0.001 . Similar number of primary and secondary infertility was seen in Shamila $\mathrm{S}$ et al. ${ }^{10}$ $82.48 \%$, 17.52\%, S. Samal et al. ${ }^{11} 62 \%, 38 \%$.

Maximum conception was seen when there was presence of good number of sperm count which was statistically significant $\mathrm{P}=0.015$. There were 7 (63.63\%) conception when sperm count was more than 20 millions, 3 (27.27\%) conception when count was in between 16-20 millions, \& $1(9.09 \%)$ conception when count was in between 11-15 millions. In agreement with Kang and Wu et al. $1996^{12}$ who described a slight though statistically significant higher pregnancy rate in relation to the number of motile sperm inseminated. Lucette et al. $1998^{13}$ stated, overall significant increase in pregnancy rate was found with an increasing number of motile spermatozoa. A significant increase in pregnancy rate was found when less than 0.5 million versus greater than 0.5 million spermatozoa were inseminated

In present study it shows that there were $8(16 \%)$ conception when women were under 30 year, $3(6 \%)$ conception when age was between 31-35 years, and there were no conception seen in advanced age. In Similar study done by Collins et al. $1995,{ }^{14}$ Scott et al. $1995^{15}$ reported decrease in female reproductive capacity with advancing age. The ovarian reserve diminishes with advancing age, but there is great variability in the timing of the onset of impaired reproductive potential for individual women

When observed in terms of duration of infertility maximum number of conceived patients were amongst 4-6 years duration of infertility $6(54.30 \%), 2(18.10 \%)$ patients conceived when duration of infertility was 1-3 years, there were $2(18.10 \%)$ conception between $7-9$ years duration of infertility and $1(9.09 \%)$ conception in 10-12 years of married life. life. In agreement with Kamath et al. ${ }^{16}$ stated that the success rate was significantly lower, with an increase in duration of infertility (5.36 vs. 6.71 years, $P=0.032$ which was strongly significant $\mathrm{P}<0.05$. As duration of infertility increases, age of couple also increases so fertility decreases.
Maximum number of patients conceived with monofollicular growth of ovary and it was significantly statistically. Although different studies proved that multifollicular growth is more favourable for conception. In present study it was found that, 7 (63.49\%) patients conceived when there was presence of one pre ovulatory follicle of $>16 \mathrm{~mm}$ i.e. monofollicular response was seen, $3(27.27 \%)$ patients conceived when follicles was 2 or more and when multi follicular $>4$ follicle was present $1(9.09 \%)$ patient conceived.

No case of ovarian hyper stimulation syndrome was found in the present study. And in agreement with Kamath et al. $2010^{16}$ a monofollicular response was observed in $71.87 \%$ of the cycles. Maybe because we used only clomiphene for $22(44 \%)$ patients we found monofollicular development mostly, which was statistically insignificant.

On contrary, Tomlinson et al., ${ }^{17}$ Hughes et al., ${ }^{18}$ Nuojuahuttunen et al. $1999^{19}$ stated in their study that chance of conceiving when only one follicle was produced was only $7.6 \%$, whereas with two follicles this chance increased to $26 \%$

In present study majority of patients had good endometrium, but it was statistically non-significant. In present study it was seen that when endometrial thickness was $>10 \mathrm{~mm}$ there were $7(14 \%)$ conception, when endometrial lining was in between 6-10 $\mathrm{mm} \mathrm{4(8 \% )}$ conception was noted, but when it was thinner $<6$ no conception was seen.

In present study maximum number of conception was in $\mathrm{CC}+\mathrm{HMG}+\mathrm{hCG}$ as $6(54 \%)$ women conceived but it was not statistically significant, in $\mathrm{CC}+\mathrm{hCG} 2$ (18.18\%) patients conceived, in $\mathrm{CC}+\mathrm{FSH}+\mathrm{hCG} 2(18.18 \%)$ patient conceived, in $\mathrm{CC}+\mathrm{HMG}+\mathrm{GnRHA} 1$ (9.09\%) patient conceived. Due to high cost of GnRH agonist it is unaffordable for many people and as it is a rural area patients are generally of low socioeconomic status.

11 patients got pregnant and rest 39 had failure of pregnancy after intrauterine insemination. Successful pregnancy achieved by intrauterine insemination, pregnancy rate was $22 \%$ per patient and $15.27 \%$ per IUI cycle. Our results are in consonance with studies done by Zadehmodarres et al. ${ }^{20}$ (22\% per cycle), Yousefi et al. ${ }^{21}$ (27\% per patient, $6 \%$ per cycle), Araujo et al. ${ }^{22}(29.7 \%$ per cycle), Merviel et al. ${ }^{23}$ ( $14.7 \%$ per cycle).

Outcome of conception after IUI i.e. 4 patients had live birth, so live birth per couple is $8 \%$, there were 2 ongoing pregnancy, so on-going pregnancy rate per couple is $4 \%, 3$ patient had spontaneous abortion, so abortion rate per couple is $6 \%$, and 2 patients had blighted ovum, so it was $4 \%$.

And majority of patient had failure of pregnancy after the treatment of IUI. 
Table 1: Logistic regression model for predicting the success of IUI treatment.

\begin{tabular}{|lccl|}
\hline Variables & $\mathrm{OR}$ & $\mathrm{CI}(\mathbf{9 5} \%)$ & P value \\
\hline $\begin{array}{l}\text { Female age }<\mathbf{3 0} \text { (years) } \\
\text { (years) }\end{array}$ & 1.36 & $0.97,2.37$ & 0.048 \\
\hline Number of follicles & 2.13 & $1.13,3.21$ & 0.031 \\
\hline 1 & 2.28 & $1.11,3.16$ & 0.089 \\
\hline 2 & 1.36 & $0.87,2.11$ & \\
\hline 3 & 1.24 & $0.68,1.96$ & \\
\hline IUI cycles & & & \\
\hline 1 & 1.02 & $0.87,1.67$ & 0.046 \\
\hline 2 & 1.36 & $0.78,1.87$ & \\
\hline 3 & 3.12 & $1.13,4.56$ & \\
\hline Thickness of endometrium & & & \\
\hline 7 & 0.45 & $0.22,1.02$ & 0.161 \\
\hline 8 & 0.64 & $0.32,1.12$ & \\
\hline 9 & 0.78 & $0.22,1.33$ & \\
\hline 10 & 0.43 & $0.12,0.89$ & \\
\hline
\end{tabular}

On the basis of analysis of successful outcome of IUI it can be said that the patients with best prognosis are the one with age $<30$ years, lesser duration of infertility, good motile spermatozoa, preovulatory follicle, good endometrial thickness, \& semen preparation are certainly the cornerstones for successful intrauterine insemination.

\section{CONCLUSION}

Infertility is a big stigma in rural population. To formulate affordable and feasible treatment is another dilemma and is also always not easy. IUI is cost effective, least invasive and easily affordable with minimal efforts.

In our study, out of 50 patients enrolled for the study and 72 IUI cycles were given, eleven patients got pregnant, so pregnancy rate per couple was $22 \%$, and pregnancy rate per cycle was $15.27 \%$.

Four patients had live birth, so live birth per couple was $8 \%$. There were two on going pregnancy, so on-going pregnancy rate per couple is $4 \%$. Three patients had spontaneous abortion, so abortion rate per couple was $6 \%$. Two patients had blighted ovum, so it was $4 \%$. No case of OHSS was found. No case of ectopic pregnancy was found. No multiple pregnancy was recorded.

IUI is cheap, cost effective treatment in infertility who cannot afford to go to for higher treatment IVF.

\section{Limitation of the study}

- This was the first kind of study, at our institute with establishment of IUI very recently hence required lot of counselling for couple selection.
- The results of the study cannot be generalized as it requires large sample size. Although our results were almost similar to other large scale RCT'S.

Funding: No funding sources

Conflict of interest: None declared

Ethical approval: The study was approved by the institutional ethics committee

\section{REFERENCES}

1. Cooper TG, Noonan E, von Eckardstein S, Auger J, Baker HW, Behre HM, et al. World Health Organization reference values for human semen characteristics. Hum Reprod Update. 2010;16(3):231-45.

2. Vayena E, Rowe P. Peterson H. Assisted reproductive technology in developing countries: why should we care? Fertil Steril. 2002;781:13-5.

3. Vayena E, Rowe P, Griffin D, Van Look P, Turmen T. Forward, current practices and controversies in assisted reproduction. In: Vayena E, Rowe P, Griffin D, eds. Report of a Meeting on Medical, Ethical, and Social Aspects of Assisted Reproduction, 2001 17-21 Sept. Geneva, Switzerland: WHO; 2002: xv-xxi.

4. Cramer DW, Walker AM, Sciff. Statistical methods in evaluating the outcome of infertility therapy. Fertil Steril. 1979;32:80.

5. Agarwal SK, Buyalos RP. Clomiphene citrate with intrauterine insemination: is it effective therapy in women above the age of 35 years? Fertil Steril. 1996;65:759-63.

6. Bagis T, Haydardedeoglu B, Kilicdag EB, Cok T, Simsek E, Parlakgumus AH. Single versus double intrauterine insemination in multi-follicular ovarian hyperstimulation cycles: a randomized trial. Hum Reprod. 2010;25:1684-90.

7. Duran HE, Morshedi M, Kruger T, Oehninger S. Intrauterine insemination: a systematic review on determinants of success. Hum Reprod Update. 2002;8:373-84.

8. Nuojua-Huttunen S, Tomas C, Bloigu R, Tuomivaara L, Martikainen H. Intrauterine insemination treatment in subfertility: an analysis of factors affecting outcome. Hum Reprod. 1999;14:698-703.

9. Guzick DS, Carson SA, Coutifaris C, Overstreet JW, Factor-Litvak P, Steinkampf MP, et al. Efficacy of superovulation and intrauterine insemination in the treatment of infertility. N Engl J Med. 1999;340:17783.

10. Shamila S, Sasikala SL. Primary report on the risk factors affecting female infertility in South Indian districts of Tamil Nadu and Kerala. Indian J Community Med. 2011;36(1):59-61.

11. Samal S, Dhadwe K, Gupta U, Gupta NK. Epidemiological study of male infertility. Indian Med Gazette. 2012 May;146(5):174-80.

12. Kang BM, $\mathrm{Wu}$ TC. Effect of age on intrauterine insemination with frozen donor sperm. Obstet Gynaecol. 1996;88:93-8. 
13. Westerlaken LA, Naaktgeboren N, Helmerhorst FA. Evaluation of pregnancy rates after intrauterine insemination according to induction, age and sperm parameters. J Assist Reprod Genet. 1998;15:359-64.

14. Collins JA, Burrows EA, Willan AR. The prognosis for live birth among untreated infertile couples. Fertil Steril. 1995;64:22-8.

15. Scott RT, Opsahl MS, Leonardi MR, Neall GS, Illions EH, Navot D. Life table analysis of pregnancy rates in a general infertility population relative to ovarian reserve and patient age. Hum Reprod. 1995;10:1706-10.

16. Mohan S. Kamath, Priya Bhave, T. K. Aleyamma, Raju Nair, A. Chandy, Ann M. Mangalaraj, et al. Predictive factors for pregnancy after intrauterine insemination: a prospective study of factors affecting outcome; J Hum Reprod Sci. 2010 SepDec;3(3):129-34.

17. Tomlinson $\mathrm{M}$, Amissah-Arthur J, Thompson $\mathrm{K}$, Kasraie J, Bentick B. Infertility: prognostic indicators for intrauterine insemination (IUI): statistical model for IUI success. Hum Reprod. 1996;11:1892-6.

18. Hughes E, Brown J, Collins J, Vanderkerchove P. Clomifene citrate for unexplained subfertility in women. Cochrane Database Syst Rev. 2000;(2):CD000057.

19. Nuojua-Huttunen S, Tomas C, Bloigu R, Tuomivaara $\mathrm{L}$, Martikainen $\mathrm{H}$. Intrauterine insemination treatment in subfertility: an analysis of factors affecting outcome. Hum Reprod. 1999;14:698-703.
20. Shahrzad Zadehmodarres, Belgheis Oladi, Shahrbanoo Saeedi, Fatemeh Jahed, Haleh Ashraf. Intrauterine insemination with husband semen: an evaluation of pregnancy rate and factors affecting outcome. J Assist Reprod Genet. 2009;26:7-11.

21. Behpour Yousefi, Azam Azargon. Predictive factors of intrauterine insemination success of women with infertility over 10 years. J Pak Med Assoc. 2011 Feb;61(2):165-8.

22. Lígia FP de Araújo, Edilberto de AraújoFilho, Cássio L. Fácio, Márcia CO. Bossoni, Ligiane A. MachadoPaula, José E. Corrente, et al. Efficacy of sperm motility after processing and incubation to predict pregnancy after intrauterine insemination in normospermic individuals. Reprod Biol Endocrinol. 2013;11:101.

23. Merviel P, Heraud MH, Grenier N, Lourdel E, Sanguinet P, Copin H. Predictive factors for pregnancy after intrauterine insemination (IUI): an analysis of 1038 cycles and a review of the literature. Fertil Steril. 2010;93(1):79.

DOI: $10.5455 / 2320-1770$. ijrcog20150220

Cite this article as: Khemka SS, Shrivastava D, Hariharan C, Jaiswal A. Role of intrauterine insemination in infertile couple seeking care at Acharya Vinobha Bhave rural tertiary care hospital. Int J Reprod Contracept Obstet Gynecol 2015;4:103-8. 